\title{
PARA UMA SOCIOLOGIA DO CRIME E DA PENA NA OBRA DE ÉMILE DURKHEIM: AS REGRAS DO MÉTODO SOCIOLÓGICO
}

TOWARDS A SOCIOLOGY OF CRIME AND PUNISHMENT IN THE WORK OF ÉMILE DURKHEIM: THE RULES OF THE SOCIOLOGICAL METHOD

Sílvia Alves ${ }^{1}$

Universidade de Lisboa

\section{Resumo}

Este artigo tem como objetivo reconstruir a sociologia do crime e da punição de Émile Durkheim, partindo da interpretação da obra As regras do método sociológico. Palavras-chaves

Émile Durkheim. Conceito sociológico. Crime.

\section{Abstract}

This article aims to reconstruct the sociology of crime and punishment of Émile Durkheim, starting from the interpretation of the work The rules of the sociological method.

Keywords

Émile Durkheim. Sociological concept. Crime.

\section{Em busca de um conceito sociológico de crime}

a. Se, num olhar mais desprevenido, o crime e a pena não parecem ocupar senão um papel acessório e instrumental na obra de Émile Durkheim (1858-1917), uma observação mais atenta permite

\footnotetext{
${ }^{1}$ Professora Associada da Faculdade de Direito da Universidade de Lisboa (Licenciatura, Mestrado e Doutoramento). Doutora pela Faculdade de Direito da Universidade de Lisboa. Coordenadora da Linha de Pesquisa Crime e Castigo do Centro de Investigação THD - Universidade de Lisboa.
} 
rapidamente perceber que boa parte das reflexões daquele que parece ter permanecido um professor de moral se encontra entrelaçada nos temas mais estruturantes da sua sociologia, como as formas de solidariedade ou o método sociológico. Não obstante as críticas que recebeu e a natural usura do tempo, o contributo de Durkheim para a sociologia do crime e da pena permanece nos nossos dias incontornável e instigador de novas leituras. A reconstituição do seu pensamento é apenas possível através do cotejo de um significativo conjunto de textos esparsos, mais ou menos conhecidos, que aqui iniciamos com $\mathrm{As}$ regras do método sociológico.

b. As regras do método sociológico encerram uma desafiadora reflexão sobre o crime. A sua primeira edição em livro data de 1895, mas a obra fora publicada no ano anterior, sob a forma de artigos, na Revue philosophique. Em menos de quinze páginas, Durkheim procede a uma aplicação das regras antes enunciadas sobre a distinção entre o normal e o patológico, ou seja, sobre a definição da própria normalidade dos fatos sociais: o que é, para a sociologia, um fato social normal? Para que a sociologia fosse uma "ciência de coisas" seria necessário que a generalidade dos fenómenos fosse tomada como critério da sua normalidade.

c. No capítulo II, sobre as "Regras relativas à observação dos fatos sociais", Durkheim enuncia a mais impactante regra do método sociológico, "a primeira e a mais fundamental", recebida aliás não sem perplexidade: "considerar os fatos como coisas". Entende-se assim que os fatos sociais são dotados de exterioridade - porque são exteriores aos indivíduos ou existem fora das consciências individuais - e de um poder imperativo e coercitivo, em virtude do qual se lhes impõem. Com esta regra, Durkheim abre uma cesura face ao passado: "até agora, 
a sociologia tem tratado mais ou menos exclusivamente, não de coisas, mas de conceitos". O próprio Comte (1798-1857) bem podia ter proclamado um método positivo, baseado na observação dos fatos, de forma a induzir conclusões e enunciar as leis da sociedade, mas na realidade acabara por ser "filósofo enquanto sociólogo" e "sociólogo enquanto filósofo" (Aron, 2010, 114).

Na procura dos traços exteriores dos fatos sociais, tão objetivos quanto possível, Durkheim confia ao direito um papel particularmente decisivo, uma vez que a vida social, onde existe de forma duradoura, tende a tomar uma "forma definida" e a organizar-se: "o direito nada mais é que essa mesma organização no que ela tem de mais estável e de mais preciso". Em Da divisão do trabalho social (1893), o estudo da solidariedade social, das suas formas e evolução havia sido realizado através do sistema das regras jurídicas que a exprimem (Livro I, Capítulo I, III). Se a solidariedade é um fenómeno totalmente moral que não se presta à observação, o direito é, ao invés, o seu "símbolo visível". Um "indicador metodológico" que a permite "medir" indiretamente (Trevino, 2008, 239), tornando "visível o tipo de estrutura social existente" (Sabadell, 2013, 44).

Ao tomar como objeto de investigação fenómenos previamente definidos através de características exteriores comuns e agregando todos os apresentam tais características, o sociólogo mantém-se "com os pés assentes na terra" e espelha a "natureza das coisas". Neste contexto, Durkheim enuncia, em As regras do método, um primeiro conceito de crime enquanto "ato punido". Serão neste sentido crimes todos os atos dotados de uma "característica exterior": uma vez praticados, determinam, da parte da sociedade, "essa reação particular a que se chama pena” (Capítulo II, II, 2.o). Definindo o crime através da pena, antevê a acusação a que se expunha: "fazer derivar o crime da pena ou, segundo uma citação bem conhecida (...) ver no cadafalso e 
não no ato expiado a origem da vergonha". O conceito que apresenta constitui, contudo, somente um ponto de partida, "um primeiro ponto de apoio"; não é a pena que "faz o crime, mas é através dela que o crime se nos revela exteriormente e é dela que teremos que partir se quisermos chegar a compreendê-lo". Em suma, numa definição sociológica, ampla e prévia ou "metodológica" (Digneffe, 1998, 368), o crime é todo o comportamento sancionado através de uma pena.

\section{A crítica de Garofalo. A teoria do "delito natural" e a "anomalia do delinquente"}

a. Durkheim opõe-se expressamente ao conceito - também sociológico - de crime defendido por Raffaele Garofalo (1851-1934), que, na sua Criminologia, teria adotado uma noção (restrita) de "crime natural". Em causa não estariam, portanto, todos os comportamentos reprimidos através das penas, mas somente aqueles que ofendiam "a parte média e imutável do senso moral”. Os sentimentos morais que desapareciam com a "evolução" não eram, para o criminólogo italiano, fundados na "natureza das coisas". Ora, segundo Durkheim, "em virtude de uma conceção muito pessoal de moralidade" e, por consequência, de uma ideia (prévia) de crime, o seu opositor condiciona e transfigura o tratamento sociológico da criminalidade. Essa ideia, depurada, supõe que a "evolução moral" "carreia toda a espécie de escória e de impurezas que elimina depois progressivamente". Ao invés, para Durkheim, o crime "anormal", que poderíamos também designar como "não-natural" ou "artificial", é igualmente crime.

“As partes variáveis do sentido moral não são menos fundadas na natureza das coisas do que as partes imutáveis; as variações, por que passaram as 
primeiras, testemunham simplesmente que as próprias coisas variaram. (...) os atos taxados como crimes pelas sociedades primitivas, e que perderam essa qualificação, são realmente criminosos em relação a essas sociedades, exatamente como os que continuamos a reprimir hoje em dia. Os primeiros correspondem às condições em transformação da vida social, os segundos às condições constantes; mas não são mais artificiais uns que outros." (As regras do método sociológico, Capítulo II, II, 2º)

b. A Criminologia (1885) de Garofalo, que também foi magistrado, atesta o manifesto propósito de aproximar do direito a "scuola criminale positiva". A edição portuguesa, de 1893, dirigida aos mercados literários de Portugal e do Brasil e prefaciada pelo psiquiatra Júlio de Mattos (1856-1922), reflete já as críticas surgidas depois da primeira edição.

Segundo Garofalo, os estudos dos "naturalistas" - centrados nos delinquentes e ignorando o delito - não haviam produzido um impacto útil no direito penal. Modifica por isso a perspetiva de análise, propondo-se tomar como ponto de partida o crime ou, mais rigorosamente, uma "noção sociológica de delito". Esta noção prévia da que depende a definição do delinquente - constitui tarefa que atribui ao "criminalista sociólogo": a "ele e não ao homem da lei cumpre definir o delito". Propõe-se assim estudar os "verdadeiros delitos", as suas "causas naturais" e os seus "remédios".

$\mathrm{O}$ conceito de delito que adota é realmente um conceito restrito, como resulta do comentário de Durkheim. Uma específica categoria está em causa: o delito natural.

"Existirá o delito natural ou, o que vale o mesmo, haverá um certo número de atos que a consciência popular em determinadas condições considere sempre criminosos?" (Garofalo, Criminologia, Primeira Parte, Capítulo I, I) 
A investigação a que procede começa por inquirir se, entre os delitos "previstos nas nossas leis atuais", existem "alguns" considerados puníveis em todos os tempos e lugares. Aparentemente, estaria em causa um conceito capaz de transcender o tempo e o espaço. A imensa variação histórica e geográfica leva-o, no entanto, a renunciar à hipótese de encontrar "atos universalmente considerados criminosos e universalmente punidos". Muda então o "método" e substitui a análise dos "atos" pela análise dos "sentimentos". No delito vê então, invariavelmente, a lesão dos "sentimentos mais profundamente radicados no espírito humano", aqueles que no seu conjunto formam o "senso moral".

Pondo de parte o homem pré-histórico e as tribos "selvagens degeneradas ou insuscetíveis de desenvolvimento", que considera uma "anomalia na espécie humana", tenta isolar os "sentimentos morais" "definitivamente adquiridos pela parte civilizada da humanidade e que formam a verdadeira moral contemporânea, não suscetível de perderse, mas, pelo contrário, de progredir incessantemente".

Garofalo constrói o conceito de delito natural sobre os alicerces de uma moralidade atual e historicamente adquirida, produto paulatino da evolução e do progresso. É a moralidade da sociedade contemporânea e civilizada ou "culta". Não se trata de uma "moral absoluta", mas de uma "moral relativa", resultante da adaptação do indivíduo à sociedade. Afastando a ideia de "universalidade absoluta da moral", admite, ainda assim, a "identidade de alguns instintos morais" numa parte considerável da espécie humana. Esses "instintos morais inatos", não dependentes do "raciocínio individual", constituem um "património hereditário comum".

O "senso moral" de Garofalo integra instintos altruístas, diretamente tendentes ao bem dos outros e que reduz à benevolência e à justiça. Existiria em todos os povos "não selvagens" um sentimento 
altruísta universal, aquisição definitiva da humanidade que atingiu um certo grau de evolução: a piedade na sua forma negativa, expressão da benevolência que se traduz na abstenção de certos atos motivada pela "repugnância a produzir uma dor" física. Em todos os tempos, consideram-se criminosos os atos ofensivos desse sentimento, salvo os necessários à salvação pública, restrição que explica nomeadamente a guerra. Quanto ao sentimento de justiça, constata que, numa "sociedade civilizada", o sentimento de respeito pelas coisas de ordem moral se junta ao sentimento de respeito pelas de ordem física, fundindo-se de modo indissolúvel. O termo probidade é escolhido para designar de modo mais preciso esse respeito pela propriedade alheia.

"De tudo o que acaba de ser dito precedentemente pode concluir-se que o elemento de moralidade necessário para que a consciência pública qualifique de criminosa uma ação é a ofensa feita à parte do senso moral formado pelos sentimentos altruístas de piedade e de probidade - não, bem entendido, à parte superior e mais delicada deste sentimento, mas à mais comum, à que se considera património moral indispensável de todos os indivíduos em sociedade. Essa ofensa é precisamente o que nós chamamos delito natural." (Garofalo, Criminologia, Primeira Parte, Capítulo I, IV)

Para definir o crime não basta a imoralidade e a nocividade; é necessário algo mais: uma "falta anormal da parcela mínima e mais comum" dos sentimentos altruístas. O crime é deste modo "uma espécie particular de imoralidade", que envolve crueldade ou improbidade. O crime ofende a moralidade elementar de um povo civilizado e revela anomalias naqueles que os praticam. Porque mesmo numa "sociedade culta" existem indivíduos "cuja moralidade não corresponde à da generalidade da população". Neles falta aquela parte do senso moral que a evolução tornou quase universal, formada por 
sentimentos que são a base da moral moderna e que pelo progresso moral da humanidade tendem a aperfeiçoar-se incessantemente.

c. Do conceito de delito natural Garofalo faz derivar a ideia segundo a qual o criminoso padece de uma "anomalia moral", sendo o próprio crime, nessa perspetiva, "o sintoma de uma anomalia moral".

O "tipo delinquente" padece de uma anomalia, que existe sempre e se manifesta quer pela ausência completa de senso moral, quer pela simples fraqueza dos sentimentos altruístas. Garofalo contradiz a distinção entre delinquentes que são "seres organicamente anormais" e delinquentes normais ou "fortuitos", para os quais a explicação do crime se deve às circunstâncias "fortuitas" em que se encontravam no momento da sua perpetração. Todos padecem, em maior ou menor grau, de uma anomalia, a anomalia moral, e todos são, em qualquer dos casos, seres anormais.

"Eu julgo inteiramente errónea esta ideia. Sem dúvida, as circunstâncias externas - o ambiente moral ou físico, as tradições, os exemplos, o clima, as bebidas, mil outras - contribuem em muitos casos para a degenerescência do delinquente ou para a dos seus progenitores. É este um ponto indiscutível de que adiante nos ocuparemos. O que neste momento desejamos estabelecer é o seguinte: - que o criminoso, muitas vezes psiquicamente anómalo, o é sempre moralmente; - que essa anomalia, colocando-o em condições de inferioridade relativamente à raça a que pertence, é, sociologicamente, uma degeneração, imputável, como veremos, a causas hereditárias ou do meio; e que, portanto, não são as circunstâncias em que o delinquente se encontra, mas a sua degeneração individual, a causa do crime" (Garofalo, Criminologia, Segunda Parte, Capítulo I, IV)

Em suma, a anomalia moral é verdadeiramente a causa do crime. As "circunstâncias externas" poderão concorrer para essa degenerescência (individual). Constituem "as causas diretas e 
imediatas da determinação voluntária num dado momento e numa dada ordem de fatos", mas, observa Garofalo, essas circunstâncias atuam de modo diverso sobre os indivíduos e nem sempre conduzem ao crime. E não admite que um homem "moralmente bem organizado" cometa um crime por puro efeito das circunstâncias externas. $\mathrm{O}$ autor de $A$ superstição socialista (1895) avalia deste modo a miséria, que era já então apontada como causa dos crimes. Contudo, muitos, em idênticas circunstâncias, não delinquem; é necessário algo mais: precisamente a anomalia. O "meio ambiente" ou o "mundo externo" atuam somente como um detonador.

Para Garofalo, não existe pluralidade de causas do crime, rejeitando que este seja simultaneamente o efeito de "causas orgânicas individuais", de "causas físicas externas" e de "causas sociais". É estritamente o efeito de "causas individuais", que atuam num "particular ambiente físico ou em particulares contingências sociais" e que também se podem verificar para aqueles não praticam crimes, tendo, portanto, o caráter de meras "causas ocasionais". A causa do crime é o "modo de ser especial" ou anormal do indivíduo que "a natureza criou delinquente". Inversamente, a resistência a semelhantes circunstâncias "é sempre o sinal da normalidade".

Garofalo clarifica deste modo a classificação dos delinquentes que apresentara na primeira edição, em que distinguia os delinquentes "instintivos" e "fortuitos". Em ambos existe "falta de repugnância" pelo crime, mas, enquanto nos primeiros se verifica uma "absoluta ausência de senso moral e omnipotência dos instintos egoístas", nestes existe uma mera "debilidade orgânica" ou "incapacidade de resistência às provocações malévolas do mundo externo". A sua degenerescência é mais adquirida do que hereditária. 
"O crime não é, pois, o efeito direto e imediato das circunstâncias externas; está sempre no indivíduo e é a revelação de uma natureza degenerada, quaisquer que sejam as causas, antigas ou recentes, dessa degeneração. Neste sentido, o delinquente fortuito não existe." (Garofalo, Criminologia, Segunda Parte, Capítulo I, IV)

d. Esta visão do crime e do criminoso defrontou-se com críticas, quer de voluntaristas, quer de fatalistas. Os primeiros recusavam admitir o "fatalismo de uma vontade escrava das tendências e dos instintos". No entanto, não encontramos em Garofalo uma negação do livre arbítrio: "erraria quem quer que me atribuísse a ideia de que toda a tendência criminosa deve fatalmente conduzir a uma ação”. A tendência criminosa, a falta de senso moral, é somente uma "predisposição" ou uma "condição propícia” à perpetração do crime e pode ser obstaculizada através de "condições externas". Do lado oposto, perfilavam-se aqueles que viam na anomalia do delinquente uma verdadeira patologia, uma forma de alienação, a "loucura moral", como se a criminalidade constituísse um "capítulo da loucura". O delinquente seria, nesta perspetiva, invariavelmente um doente. Garofalo distingue a razão e o sentimento; a "faculdade de ideação" e a "faculdade de emoção". E conclui: "os nossos delinquentes instintivos não são sempre doentes". Entre a doença e a saúde coloca uma "zona média de limites pouco precisos”, a anomalia. A perversão moral não é entendida como uma doença, uma vez que "não perturba nenhuma função orgânica, nem altera a vida fisiológica, mas apenas torna o indivíduo incompatível com o meio". Ela é uma "anomalia não patológica". Em contrapartida, rejeita a ideia de "loucura moral". A extrema perversidade pode ser, em certos casos, patológica, mas se corresponde a um mero "instinto criminoso" ou a uma mera anomalia moral, "conquanto sempre orgânica, não constitui uma doença”. É uma “anomalia congénita de caráter" ou a "fisionomia moral particular" do 
indivíduo delinquente. Ou seja, o delinquente não é um ser normal, mas, simultaneamente, não é, em regra, um doente; somente um individuo anómalo. Se no louco o crime é "determinado por uma excitação interna, não provocada pelos estímulos do meio ambiente", no "delinquente instintivo", o delito é "provocado pelos mesmos impulsos que solicitam o homem normal e que nos delinquentes não encontram a combatê-los a resistência do senso moral ausente".

A distinção entre doença e anomalia tem, como reconhece, uma "grande importância" porque através dela pode Garofalo justificar a pena de morte: "seria um ato bárbaro, se os delinquentes fossem seres em sofrimento e com direito à nossa compaixão e mesmo à nossa simpatia, porque o crime, nesta hipótese, seria um incidente da doença e não o efeito do próprio caráter e temperamento".

e. O prefácio de Júlio de Mattos merece a propósito uma nota final. Compara os delinquentes, "espíritos inferiores", aos micróbios, numa imagem que o próprio Durkheim adotaria em As regras do método. As "legiões microbianas" são, para o psiquiatra português, o "inimigo social".

Opõe-se de forma veemente ao "clássico direito penal", "ciência metafísica e de conjetura", que "imaginava" os delinquentes "semelhantes a todos os outros homens", livres e responsáveis. Opõe a "velha penologia, ramo infecundo da ciência metafísica do direito" à "penologia moderna, aplicação prática e direta da antropologia criminal". Opõe a pena enquanto "instrumento metafísico de expiação" à pena enquanto "arma positiva de defesa". A sua adesão não obsta a que assinale um ponto de divergência quanto ao entendimento de que a "loucura moral" ou ausência de senso ético não seria uma doença, mas somente uma anomalia. Comenta certeiramente: fica assim a porta aberta para se justificar a aplicação da pena de morte: 
"acha o criminalista italiano que, se os reputássemos doentes [aos "indivíduos destituídos de senso moral"], tal aplicação repugnaria, ao passo que ela é racional e aceitável, se os considerarmos seres anormais e monstruosos".

\section{O crime como "fenómeno da sociologia normal" e "fator da saúde pública"}

a. Durkheim constata que existia então unanimidade na criminologia quanto à natureza patológica (ou anormal) do crime, não obstante as diferentes explicações dessa morbidez: "se há fato cujo caráter patológico parece incontestável é o crime". Não obstante, rompe radicalmente com esta visão, apresentando-o como um "fenómeno normal" ou um "fato da sociologia normal". Porque a criminalidade existe, inevitavelmente, em todas as sociedades. Nos "tipos inferiores" e nos tipos superiores ou "mais elevados" ("plus élevés”). E em qualquer época. É impossível conceber uma sociedade sem crime.

"Não existe, portanto, fenómeno que apresente da forma mais incontestável todos os sintomas da normalidade, uma vez que aparece estreitamente ligado às condições de toda a vida coletiva" (As regras do método sociológico, Capítulo III, III)

Em suma, "o crime é normal porque uma sociedade isenta dele é completamente impossível". Contudo, a conceção do crime como um fenómeno da sociologia normal não implica, para Durkheim, que o criminoso seja entendido como um indivíduo "normalmente constituído sob o ponto de vista biológico e psicológico". Os dois problemas - a normalidade do crime e a conceção do criminoso como 
ser anormal - são, de modo expresso, considerados independentes um do outro.

Lançando os alicerces de uma sociologia empírica, Durkheim faz uso da estatística, então já disponível, permitindo seguir a "marcha da criminalidade" desde o início do século XIX. Observa que a taxa de criminalidade não registava qualquer diminuição; ao invés, aumentara por toda a parte. Não era, portanto, viável supor uma "regressão", em que o crime viesse a perder o caráter de "fenómeno normal". A criminalidade permanece; e muda somente de forma. Nesse sentido, "não existe uma criminalidade". Os comportamentos qualificados como criminosos não são necessariamente sempre os mesmos ao longo da história.

A normalidade do crime não obsta a que este possa tomar "formas anormais", o que sucede, por exemplo, quando a taxa de criminalidade é "exagerada" ou excessivamente elevada num certo "tipo social" e numa fase determinada do seu desenvolvimento. Se a criminalidade é em si mesma normal, uma taxa excessivamente alta ou exígua têm uma natureza mórbida.

Durkheim atinge uma conclusão que ele próprio qualifica como aparentemente "paradoxal" e desconcertante: classificar o crime entre os fenómenos da "sociologia normal" não significa somente que este constitui um "fenómeno inevitável", ainda que lamentável, mas também que é "um fator da saúde pública, uma parte integrante de toda a sociedade sã". Não se trata, portanto, de um fenómeno normal porque meramente inevitável e, também, ainda assim, pernicioso. Numa sociedade saudável, o crime é necessário. De forma ainda mais radical, Durkheim estilhaça uma ideia ancorada numa imagem secular: o crime deixa de ser entendido como uma "doença social". 
b. Sabemos que o crime existe e sempre existiu nas sociedades históricas, mas: será que pode ser erradicado, como parece até desejável? Para que, hipoteticamente, o crime desaparecesse - ou os atos qualificados como crimes deixassem de ser praticados - seria necessário que os sentimentos que ferem ou ofendem se encontrassem presentes em todas as "consciências individuais", sem exceção e com um grau de intensidade suficiente para conter os sentimentos contrários. Durkheim faz aqui uso da sua noção substantiva de crime "um ato que ofende certos sentimentos coletivos, dotados de uma energia e de uma nitidez particulares" - parecendo dar nota de um certo relativismo ético ao entender que não é a sua "importância intrínseca" aquilo que confere a um comportamento caráter criminal, mas a que lhe é emprestada pela "consciência comum".

O evanescimento da criminalidade tornaria necessário que os sentimentos coletivos protegidos pelo direito penal de um certo povo, num determinado momento da sua história, conquistassem o respeito de todos, ou seja, adquirissem uma "intensidade superior", penetrando todas as "consciências" e eliminando completamente a inclinação ("penchant") para a sua ofensa. Mesmo que esta mera hipótese se realizasse, o crime verdadeiramente não desapareceria. Limitar-se-ia a mudar de forma. A causa que determina a eliminação das formas antigas de criminalidade conduziria ao nascimento de novos crimes. Os "estados fortes da consciência coletiva" não se reforçam sem que o mesmo suceda com os "estados mais fracos", que são o prolongamento e a forma atenuada daqueles, por isso sentidos menos intensamente pela "média das consciências", e cuja violação originava antes apenas faltas morais. Este aumento de sensibilidade da consciência social não se limita a erradicar as violações graves ou criminosas dos sentimentos coletivos; produz uma exacerbação da reprovação perante as faltas antes sentidas com menos energia. Uma consciência comum mais forte 
é também mais sensível e mais exigente. Uma "sociedade de santos" um "claustro exemplar e perfeito" - mas armada com o poder de julgar e de punir converterá simples faltas morais em verdadeiros crimes. Do mesmo modo que um homem honesto aplica às suas menores falhas uma severidade que o vulgo reserva às piores ofensas. Em suma, o crime não desaparece; simplesmente muda. As "violências contra as pessoas", observa Durkheim, eram mais frequentes em épocas em que o respeito pela "dignidade individual" era mais débil. Simultaneamente, outros comportamentos menos graves que ferem este sentimento passaram a integrar o direito penal.

A hipótese de uma elevação da "consciência moral da sociedade", em que os sentimentos coletivos estariam presentes em todos os indivíduos, sem exceção, com suficiente vitalidade para afastar não apenas os crimes, mas também as faltas morais, é irrealizável. Durkheim levanta neste ponto a afirmação de uma irrefragável "originalidade individual". Uma tal "unanimidade" ou "uniformidade", universal e absoluta, é "radicalmente impossível". Nunca os indivíduos se poderão assemelhar o suficiente. Nem sequer os "povos inferiores", em que os homens pouco podiam divergir do "tipo coletivo", desconheciam a "originalidade individual". Entre as divergências individuais fatalmente alguma apresentará um caráter criminal. O conjunto das causas que produzem a insuperável individualidade do homem oferece também uma visão potencialmente precursora sobre as causas dos crimes: "o meio físico imediato no qual cada um se encontra inserido, os antecedentes hereditários, as influências sociais de que dependemos variam de indivíduo para indivíduo e, por consequência, diversificam as consciências". Entre essas causas não se perfilam somente os antecedentes hereditários, mas também o meio físico e as influências sociais. 


\section{O crime: necessário e útil}

a. Durkheim considera incontestável - sobretudo nos nossos dias - a natural variabilidade da normatividade. A moral e o direito estão sujeitos à mudança. Mudam de um tipo social para outro tipo social. E mudam, no mesmo tipo social, quando as condições da vida social se modificam. Para tal, para que a mudança social seja possível, os "sentimentos coletivos" não podem ser refratários à mudança. Têm que ser "plásticos" ou flexíveis. E, para tal, têm que ter uma "energia moderada". Sentimentos coletivos muito fortes e firmes poderiam hipoteticamente apagar o crime da face da terra e, então, a ausência de criminalidade seria a manifestação de uma sociedade pétrea ou imobilizada e imutável. "Quanto mais fortemente se revela uma estrutura tanto maior é a resistência que ela opõe a qualquer modificação", escreve Durkheim. Neste passo, de travo "protofuncionalista", identifica os seus dois elementos integrantes, especificando que aí encontramos arranjos ou disposições "funcionais" (função) e "anatómicos" (estrutura).

Em suma, a conformação dos sentimentos coletivos gera, no seu devir histórico, a moral e o direito vigentes - e, por consequência, a definição do crime - mas também a mudança social ou, talvez mais exatamente, o concreto equilíbrio entre estabilidade e mudança. É desejável que a "autoridade" da consciência moral não seja excessiva, de modo a que ela própria possa "evoluir". É necessário algum espaço para a "originalidade individual". Nesse espaço, tanto podem irromper o "idealista", que "ambiciona ultrapassar o seu século", como o criminoso, que se encontra "aquém do seu tempo". Ao refletir e simultaneamente conferir à consciência moral o "estado de maleabilidade" que possibilita a "evolução" da sociedade, o crime não se apresenta, contudo, apenas como um preço a pagar e, ainda assim, 
um mal ou um mal necessário. Neste "papel útil", Durkheim reconhece-lhe somente uma "utilidade indireta".

O crime tem também uma utilidade direta porque "prepara diretamente estas mudanças"; porque antecipa e predetermina a nova forma dos sentimentos coletivos: por vezes, é mesmo "a antecipação da moral futura”. O crime de Sócrates anunciou um novo tempo. Tal como a consagração da liberdade de expressão foi antecedida por corajosas violações das regras que encerravam a sua proibição, até que estas foram revogadas. O crime pode ser um sintoma da desconformidade entre os valores do passado - acolhidos pelo direito vigente - e os valores que as novas condições sociais entretanto geraram. O crime é então o prelúdio do futuro. E, especificamente até, de um direito novo. O crime deixa de ser concebido como um "mal" que nunca é demais combater. Ao invés, um certo nível de criminalidade faz parte de uma vida social saudável. Durkheim rejeita a metáfora da doença e do remédio medicinal, mas constrói outra, aparentemente próxima: o crime é como a dor; indesejável, certamente, mas parte integrante da fisiologia normal e útil.

Patológica e sintomática de alguma "perturbação social" será uma taxa de criminalidade muito baixa ou muito alta. E observa exemplificativamente: nunca o número de ofensas corporais é tão baixo como em tempo de penúria.

“O crime é, portanto, necessário; está ligado às condições fundamentais de toda a vida social, mas, precisamente por isso, é útil; porque estas condições de que é solidário são elas mesmas indispensáveis à evolução normal da moral e do direito" (As regras do método sociológico, Capítulo III, III)

b. No prefácio da primeira edição em livro, que se segue à publicação na Révue philosophique, Durkheim clarifica a sua tese, 
respondendo às críticas que obviamente receia: "poderia acontecer que nos acusassem de querer absolver o crime"... No capítulo III, certamente o ponto mais sensível da obra, acrescenta ainda, em nota: o seu pensamento não pode ser entendido como uma "apologia do crime". O prefácio previne a reação adversa do leitor, identificando a sua eventual indignação com o senso comum, que detesta o crime e naturalmente deseja o seu total desaparecimento. O combate do sociólogo é, contudo, outro: o "estudo científico dos fenómenos sociais".

As considerações que aqui tece sobre a pena de certo modo reequilibram o seu discurso sobre a criminalidade. Se é normal a existência de crimes, não menos normal é que eles sejam punidos. Crime e pena constituem uma díade e são igualmente indispensáveis à saúde coletiva. A punição "anula" e "neutraliza" o crime, "conjurado" assim "pela ação de uma força antagónica”. A normalidade do crime não tange o fato de ser "detestado e detestável": "se o crime é normal, é com a condição de ser odiado". Na resposta à crítica de Tarde, Durkheim lembra que o mal social causado pelo crime é compensado pela pena. Na "expressão feliz" do seu contraditor, "o que é normal é o par inseparável do crime e da pena". Durkheim preocupa-se em esclarecer que a sua posição nada tem "de revolucionário"; o seu método é até "essencialmente conservador". O conhecimento científico (sociológico) do crime e da pena impõe-se pela sua objetividade e deste modo parece sobrepor-se à "vontade", às "doutrinas" e certamente também ao decisor político e ao próprio legislador.

c. A uma nova conceção de crime corresponde compreensivelmente uma renovação da "teoria da pena". Se o crime era uma doença e a pena um remédio, na imagem que atravessara os 
séculos, procurava-se a melhor forma de desempenhar essa função "medicinal". Se "o crime nada tem de mórbido", a pena deixa de ter um fim "curativo" e "a sua função deve ser procurada noutro sítio".

No penúltimo capítulo de As regras do método (Capítulo V, I), recuperando a sua reflexão contida em $D a$ divisão do trabalho social, para que remete, Durkheim alude à causa e à "função útil" da pena. Ela constitui uma "reação social" à ofensa de sentimentos coletivos dotados de particular "intensidade". A marca exterior da moralidade é diversa: uma mera "sanção repressiva difusa". Ao ser aplicada, a punição reafirma os sentimentos dominantes na sociedade e que o crime ofende; ela permite conservar esses sentimentos com o mesmo grau de intensidade, "pois não tardariam a enfraquecer se as ofensas que sofrem não fossem castigadas".

d. Esta nova criminologia - a ciência especial que tem por objeto o crime (Capítulo I, II, 2) - contrariando as ideias dominantes, acolhe um criminoso que deixa de ser visto como um "ser radicalmente insociável", um "elemento parasitário", um "corpo estranho e inassimilável”; ele converte-se num "agente regular da vida social”.

\section{Karl Marx: quando o criminoso "produz" crimes...}

Resulta impossível deixar de notar a proximidade entre a visão utilitarista do crime apresentada por Durkheim e o brevíssimo texto, não menos desafiante e desconcertante, de Karl Marx (1818-1883), incluído na obra publicada postumamente com o título Teorias sobre a mais-valia, como constituindo o Livro IV de $O$ capital, cujo primeiro volume fora editado em 1867, o único aliás ainda em vida do seu autor. Os manuscritos que deram origem às Teorias foram redigidos entre 1861 e 1863 e são, portanto, anteriores à obra de Durkheim, mas 
seriam publicados por Karl Kautsky (1854-1938) somente entre 1905 e 1910.

Nos escassos parágrafos que, numa "digressão" sobre o trabalho produtivo, dedica ao crime, o tom de Marx resulta intrigante porque, se bem que seja consistentemente sério, deixa ao leitor uma inevitável suspeita de ironia, que nunca verbaliza. Também para Marx o crime é um fenómeno normal e útil. Proporciona o desenvolvimento de atividades económicas "honestas" dedicadas ao combate ao crime; diminui a pressão sobre o mercado do trabalho, travando a descida dos salários; e preserva em geral a sociedade da estagnação.

«Um filósofo produz ideias; um poeta, poemas; um pastor, sermões; um professor, tratados, etc. Um criminoso produz crimes.» (O Capital, Livro IV, Teorias sobre a mais-valia)

A criminalidade constitui um "ramo da produção" que Marx coloca em ligação com toda a atividade produtiva da sociedade. $\mathrm{O}$ criminoso "produz" crimes. Mas também as leis penais, os professores de direito criminal, os tratados de direito penal. O combate ao crime justifica o aparelho policial, a máquina da administração da justiça. Várias profissões consideradas e ditas "úteis" são desenvolvidas na sua sombra. As fechaduras teriam atingido a perfeição atual sem o engenho dos ladrões?... Afastando-se de "preconceitos", Marx constata deste modo o impacto do crime no desenvolvimento das forças produtivas e nos esforços produtivos honestos. O crime aumenta, em suma, a riqueza nacional.

Além de impelirem uma parte da população ativa a ocupar-se no combate direto ou indireto ao crime, os delinquentes, na medida em que 
diminuem a concorrência entre os trabalhadores e a oferta de trabalho, impedem uma descida mais acentuada dos salários. O crime atua, portanto, como um fator natural de equilíbrio social.

$\mathrm{O}$ criminoso inspira ainda a literatura e, em geral, a arte. Rompe com a monotonia e a segurança quotidianas da vida burguesa. A utilidade do crime não é, nesta perspetiva, menor. Preserva a sociedade da estagnação, providenciando um poderoso estímulo ou aguilhão à concorrência e às forças produtivas. Em Marx como em Durkheim, a criminalidade encontra-se ligada à mudança social e o criminoso surge como um elemento válido da sociedade.

Em síntese, o crime é produtivo, protege os trabalhadores da degradação do preço do trabalho e, sendo um garante de equilíbrio ou estabilidade, não deixa de favorecer a mudança social.

\section{A crítica de Gabriel Tarde: criminalidade e saúde social}

a. A Revue philosophique, onde haviam sido publicados os artigos que deram origem às Regras do método sociológico, é também o palco do debate entre Gabriel Tarde (1843-1904) e Émile Durkheim. Aqui dirige Tarde, em 1895, o seu ataque a Durkheim, através do artigo Criminalidade e saúde social. E aqui responderia Durkheim, no mesmo ano, com o Crime e saúde social.

Tarde opõe-se, com algum escândalo, à forma - em rigor, apenas quase inovadora - como Durkheim apresenta a criminalidade, segundo a qual o crime seria um fenómeno normal da vida social. Sendo inevitável, faria parte de toda a sociedade sã, ou seja, era um fator da saúde pública. Mas não só: o crime seria ainda necessário e útil. A normalidade, a necessidade e a utilidade eram compatíveis com o crescimento do crime, que se verificava na sociedade contemporânea. Subjacente a esta visão estava a regra geral que 
permitia distinguir o normal do patológico ou mórbido. $\mathrm{O}$ entendimento durkheimiano da criminalidade não era senão uma consequência dessa regra geral.

b. Tarde recorda a propósito a reflexão de Francesco Poletti (1821-1896, que havia já antes refutado e que aproxima de Durkheim. Em ambos os casos, a que reconhece o mérito da originalidade, o crime surge indissociavelmente ligado à civilização contemporânea, como sua parte integrante. Para Poletti, o aumento absoluto da criminalidade podia não significar um aumento relativo. Se a atividade social ("a prosperidade industrial e financeira") aumentava, a atividade criminal crescia também. Em termos absolutos, embora não necessariamente em termos relativos. $\mathrm{O}$ aumento absoluto podia até corresponder a uma diminuição relativa, o que verdadeiramente importava.

A Tarde repugna a aproximação entre as duas progressões, a "progressão malfeitora" ("progression malfaisante") e a "progressão laboriosa" ("progression laboriseuse"). Entre o crime e o trabalho. Entre o crime e o génio. Como se a respetiva vitalidade emergisse da mesma fonte. Mas o antagonismo de Tarde manifesta-se mais amplamente contra a "indulgência crescente dos juízes e dos júris" e o "relaxamento das fibras da indignação e do desprezo públicos". Na reflexão de Durkheim, Tarde vê a oportunidade de enfrentar e clarificar o problema que considera "capital": o crime é em si mesmo bom e portanto a sua extirpação não é desejável ou sequer possível?...

c. Tarde estranha que, para Durkheim, a necessidade e a legitimidade da pena se conciliem com a utilidade e a necessidade do crime. Se o crime é útil, porquê punir? Não deveria a sociedade estar antes grata às "belas funções" e "assinalável serviço" dos criminosos?! 
Não providenciam eles inovação e empreendedorismo? Não nos mantêm "higienicamente em boa saúde nacional"? Nem se poderia dizer, para salvar a tese, que é o conjunto do crime e da pena, "simetricamente imortal e universal", que resulta socialmente higiénico e normal. Porque é ao crime impune - como a anexação do vizinho - que é atribuído o papel prestigiante de impulsionar o progresso histórico. Contudo, Durkheim ocupa-se do crime rasteiro; como é possível considerá-lo útil às sociedades, se "desliza como um intruso, obreiro do vício, parasita do trabalho, destruidor de colheitas como o granizo e não produzindo senão o contágio do seu mau exemplo?" Qual a sua utilidade?

d. A hipótese durkheimiana de uma sociedade sem crime, em que o "excesso de humanidade" e a intensidade da consciência coletiva na reprovação dos crimes, tornada mais exigente, conduziam à incriminação, com uma severidade extravagante, de meros pecadilhos ou dos mais leves atos de violência, detém a atenção de Tarde. Nesta hipótese, que considera tão remota na atualidade, encara Durkheim como o "nosso moralista". Mas, em rigor, não é apenas a reflexão de Durkheim que deixa Tarde agastado. É o seu tempo e os "progressos desastrosos da indulgência" abusiva de juízes; a tendência para "correccionalizar os crimes" e "civilizar os delitos". O "perigo da hora presente" não era a exacerbação das punições, como em épocas mais remotas, mal este que, não obstante, Tarde consideraria pior. Perdendo-se o hábito de punir, a tendência continuaria a ser a da clemência. À indulgência segue-se mais indulgência. $\mathrm{E}$ se previsivelmente o excecional e ocasional malfeitor seria banido como um parceiro desonesto num círculo de jogadores, por maioria de razão continuaríamos a ser judicialmente complacentes com as faltas não prejudiciais à sociedade. Para Durkheim, se a criminalidade baixa, a 
consciência coletiva torna-se mais exigente e a uma consciência moral mais exigente corresponde uma punição mais exacerbada das faltas menores. Para Tarde, ao invés, o "tribunal da opinião" pode ser mais severo na sua reprovação, mas não nas punições. E exemplifica: se não há adultério, a mínima proximidade entre os sexos não se torna reprovável. É antes mais livre porque sem malícia. Quanto menor for a criminalidade, menos desconfiadas serão as pessoas. Se aumentar, então sim, mais severa será a reprovação da "consciência das gentes honestas".

e. A Tarde incomoda vivamente a parificação das "variedades criminais" com as "variedades geniais". Sufocar o crime seria sufocar o génio, duas formas de "originalidade individual", identicamente distantes do tipo coletivo. E aponta uma contradição: se a pedra de toque da normalidade de um fenómeno é a sua generalidade; se o tipo médio, o tipo coletivo, é o tipo normal, Durkheim termina afirmando que o crime, fenómeno normal, favorece a eclosão de anomalias e que "a sua supressão seria uma anomalia porque teria por efeito o reino absoluto do estado normal".

Confiando escassamente nas estatísticas - "os oráculos desta sibila são frequentemente ambíguos e têm necessidade de interpretação" - comenta com ironia a diminuição da criminalidade em Inglaterra: “Ela está em vias de se tornar muito doente!". Atribui maior crédito às estatísticas especiais, circunstanciais e empreendidas por particulares. Ora, esses estudos não permitiam em caso algum atribuir a criminalidade ao génio. Encontramos um esboço das suas causas quando se investigam os "antecedentes hereditários" e a educação dos criminosos: o deboche e a preguiça, o alcoolismo e a loucura, ou ainda a ignorância. Na reincidência e na profissionalização do crime - profissão que "nada tem de útil para os outros" - a relação 
entre o génio e o crime é ainda mais distante. Ele desenvolve-se em "meios pútridos, antissociais, impróprios a toda a obra sã". Em contrapartida, quando se procuram no "meio familiar e social" as "influências favoráveis" ao aparecimento do génio científico, encontra-se em primeiro lugar "um lar essencialmente moral, puro de todo o delito e de todo o vício, aliado hereditariamente à honestidade tradicional". Além de que a segurança das existências e das propriedades em nada entrava o trabalho dos inventores ou o sucesso das empresas. Em suma, no crime não há génio e no génio não há crime.

f. Tarde apresta-se a apontar os males do crime, que aliás Durkheim não havia negado. Em primeiro lugar, o mal direto, em si mesmo óbvio. Depois, o mal indireto e visível: as prisões a construir e a conservar, assim como a máquina da justiça criminal a fazer funcionar. Finalmente, o mal indireto e não visível: a insegurança pública, a desconfiança, o tempo e o dinheiro perdidos a tentar obviar à ação dos criminosos, o mal do exemplo, a perversão do espírito público, a diminuição do respeito pela vida humana e o enfraquecimento da probidade das gentes honestas. Recusa aceitar a inviabilidade de prosseguir a erradicação do crime, desiderato que aproxima da abolição da escravatura no passado ou da eliminação do pauperismo e da mendicidade no presente. Acredita na "reforma radical" e "enérgica" do sistema judicial e penitenciário.

Sendo o crime a violação, não de todas as regras, mas somente das "mais elementares e menos discutíveis", o seu severo castigo não obstaria às "diversidades individuais" ou à "liberdade de pensar teoricamente". Uma consciência pública mais exigente, um sentimento de justiça mais desenvolvido e a pressão da moral generalizada permitiriam realizar as reformas sociais mais ousadas. Se 
o crime proporciona indiscutível criação artística ("nos esthétiques faisandées"), não nos privará também de outras e melhores formas de arte?

g. A raiz da divergência é para Tarde a (científica) distinção durkheimiana entre o normal e o patológico; a definição do normal como geral; e a identificação do tipo normal com o tipo médio. Era este o caminho "científico" que parecia obrigar a concluir que a ignorância ou a imoralidade fossem consideradas mais sãs e normais que a ciência e a virtude... Inspirando-se em Pasteur e na visão de certas doenças como um combate de um exército de células contra um exército de micróbios e, portanto, como um caso especifico de "struggle for life", define a criminalidade como um conflito entre a grande legião de gente honesta e o pequeno batalhão de criminosos. À associação entre o crime e a saúde social, opõe a visão da criminalidade como uma espécie de doença. Recusando atribuir à ciência aquilo que não lhe pertence, o normal é concebido finalisticamente como algo “ideal". O normal permanecerá, para Tarde, o extermínio do crime, da ignorância e da miséria.

\section{A resposta de Durkheim}

Em 1895, também na Revue philosophique, Durkheim responde, não sem alguma crispação, ao artigo de Tarde. Começa aí por, sistematicamente, repudiar as afirmações que, na sua opinião, lhe são indevidamente atribuídas.

(i) Nega ter afirmado que a progressão da criminalidade, constatada pela estatística, seja normal. Ele próprio havia refutado a teoria de Poletti e preparava-se para o fazer de novo, relativamente à morte voluntária, no livro que então preparava. 
Francesco Poletti (1821-1896) havia estabelecido uma relação necessária entre o desenvolvimento da criminalidade e o desenvolvimento da atividade social, de modo que, para se admitir um incremento real daquela, seria imprescindível um aumento superior desta. Se tal não se verificasse, não obstante o aumento do valor absoluto de crimes, considerava que a criminalidade não progredia verdadeiramente, o que, a partir do exame da sua evolução em França e em Itália ao longo do século XIX, concluiu ter realmente acontecido. O manual de Direito criminal português de José Caeiro da Matta (1877-1963) alude ainda à "lei de Poletti", de acordo com a qual a atividade criminosa seguia a atividade social, "normal" ou "honesta". Comenta, em nota, que raras teorias foram tão vivamente repelidas como a de Poletti. Assim tinha sucedido com Ferri, Garofalo ou Tarde. E também ele a considera destituída de "exatidão científica" (Caeiro da Matta, 1911, 215-218).

Neste passo, Durkheim clarifica o seu argumento: a criminalidade constitui um fato universal e, por consequência, apresenta o caráter da normalidade. Se, com o tempo, decrescesse, seria possível supor que essa universalidade e essa normalidade teriam um caráter temporário. Esta hipótese não era confirmada pela realidade. Tal não significava que o crescimento da criminalidade fosse normal. Admite que certos delitos aumentem com a civilização, assim como que um aumento exagerado tenha uma natureza mórbida.

(ii) Nega ter afirmado que a utilidade do crime seja impedir que a consciência coletiva incrimine mais severamente as violências menos graves, como se tal fosse um mal a evitar. Esclarece que pretendera simplesmente afirmar que é impossível conceber uma sociedade sem crime, uma vez que, se a elevação da consciência moral levasse ao desaparecimento dos comportamentos incriminados, ao mesmo tempo julgaria com mais severidade atos que antes eram avaliados com 
indulgência. A criminalidade mudaria simplesmente de forma. Daqui não se segue que essa maior severidade seja em si mesma um mal, ou um bem. Semelhante avaliação dependeria da concreta relação entre o recrudescimento do rigor e o tipo social em causa. Na cidade romana antiga, em que a "personalidade individual" era absorvida pela "personalidade coletiva", seria contraditório que a consciência coletiva se tornasse mais sensível face às ofensas contra os indivíduos. Na sociedade contemporânea, uma intensificação da deferência face à religião seria contraditória com o livre pensamento.

(iii) Nega ter afirmado que, à medida que certos crimes se tornam mais raros, as respetivas punições necessariamente endureçam. Durkheim dissocia incriminação e punição. De um aumento de severidade na incriminação não decorre uma punição mais severa. Porque o sentimento ofendido pelo crime pode ser o mesmo sentimento ofendido pela pena. Um fenómeno de compensação ocorre, impedindo que o castigo cresça como cresce a censura. Se temos mais "piedade" da vítima temos também mais compaixão pelo criminoso. A civilização aumenta a simpatia pelo género humano, tornando-nos mais sensíveis em relação às ofensas contra as pessoas, e opõe-se também às punições muito rigorosas.

(iv) Nega ter afirmado que o crime e o génio sejam dois aspetos diferentes do mesmo estado mental. Útil e mesmo necessário é que o tipo coletivo não se repita identicamente em todas as consciências individuais. Essa divergência tanto pode produzir criminosos como homens de génio. Mas recusa a identificação entre ambos.

(v) Repudia a opinião de Tarde, segundo a qual o crime "baixo e rasteiro, odiado e desprezado" ("bas et rampant, haï et méprisé") é o único de que se ocupa. Ao invés, a utilidade do crime foi demonstrada através de exemplos como o de Sócrates e, em geral, dos "filósofos heréticos de todos os tempos, precursores do livre pensamento". 
A segunda parte da resposta de Durkheim regista uma síntese clarificadora das teses que defende.

(i) O crime é normal porque se encontra ligado às condições fundamentais de toda a vida social. E se a normalidade ou inevitabilidade do crime choca Tarde - enfaticamente recusa aceitar que o seu desaparecimento seja impossível - Durkheim, confiando na cientificidade da sua construção, simplesmente riposta: uma esperança não é um fato. Comparar a erradicação da criminalidade com a erradicação da pobreza ou da escravatura supõe comparar fenómenos completamente distintos.

(ii) A criminalidade tem uma utilidade geral indireta e, por vezes, uma utilidade direta. Por um lado, é sintoma de uma sociedade em que a consciência coletiva não se impõe a todas as consciências individuais e em que, portanto, a mudança - e, com esta, a "transformação moral" - é possível. Ora, Tarde não prova que uma moral imobilizada permita ainda a sua evolução. Ou que a "evolução moral" não existe ou não deve existir. Por outro lado, por vezes - "mas por vezes somente" - o criminoso prepara a moral futura. Para Durkheim, porque a moral não é uma "grandeza matemática", mas um "sistema orgânico", a inovação moral supõe inevitavelmente alguma dose de transgressão. E uma visão fixista e imobilista da moral configura-se impossível quando procede a um alongamento da perspetiva de análise através da história, que constitui uma das marcas da sua sociologia.

(iii) A moral "é uma função social" e, como tal, deve ter um "grau de vitalidade limitado", de modo a não colidir com outras formas da atividade coletiva. Um ilimitado respeito pela vida humana, por exemplo, impediria a guerra; assim como um excessivo sentimento de apreço pela dignidade individual tornaria inviável qualquer forma de disciplina. 
Finalmente, Durkheim aponta a divergência que subjaz ao debate: a afirmação da normalidade do crime constitui uma aplicação da regra geral que estabeleceu para distinguir o normal do anormal, sobre a qual não existe entendimento entre ambos. E termina com uma profissão de fé na ciência. Nas suas palavras, a razão do seu diferendo encontra-se para além do entendimento sobre o crime; radica no fato de, ao contrário de Tarde, acreditar na ciência. E a ciência não se reduz a uma diversão intelectual ("amusement intellectuel”); deve ser dotada de "utilidade prática" e capaz, portanto, de "servir à regulamentação positiva da conduta". A si chama a ciência e a Tarde atribui o "misticismo", "o reino da anarquia na ordem prática, porque é o reino da fantasia na ordem intelectual".

\section{Referências}

ARON, Raymond. As etapas do pensamento sociológico. Alfragide: D. Quixote, 2015.

CAEIRO DA MATTA, José. Direito criminal português. Volume I. Coimbra: F. França Amado, 1911.

DIGNEFFE, Françoise. "Durkheim et les débats sur le crime et la peine”. In: Debuyst, Christian. Digneffe, Françoise. Labadie, JeanMichel. Pires, Alvaro P. Histoire des savoirs sur le crime \& la peine. Volume 2. Paris, Bruxelas: De Boeck Université, 1998, pp.357-398.

DURKHEIM, Émile. "Les règles de la méthode sociologique". In: Revue philosophique, Ano 19, N.o37 (janeiro a junho, 1894), pp.465- 
498 e 577-597; e Ano 19, N.o38 (julho a dezembro, 1894), pp.14-39 e 168-182.

DURKHEIM, Émile. Les règles de la méthode sociologique. Paris: Félix Alcan, 1895.

DURKHEIM, Émile. “Crime et santé sociale” In: Revue philosophique, Ano XX, XXXIX (janeiro a junho, 1895), pp.518-523.

DURKHEIM, Émile. As regras do método sociológico. Lisboa: Presença, 2012.

GAROFALO, Raffaele. Criminologia. Estudo sobre o delito e a repressão penal. Lisboa: Livraria Clássica Editora, 1916.

MARX, Karl. Théories sur la plus-valie (Livre IV du "Capital") [sob a responsabilidade de Gilbert Badia]. Tomo I. Paris: Editions sociales, 1974.

MARX, Karl. Teorias da mais-valia. História crítica do pensamento económico. Livro 4 de O Capital. Volume I. Rio da Janeiro: Civilização Brasileira, 1980.

POLETTI, Francesco. Il sentimento nella scienza del diritto penale: appunto psicologico-critico. Udine: Paolo Gambierasi, 1882.

SABADELL, Ana Lucia. Manual de sociologia jurídica. Introdução a uma leitura externa do direito. São Paulo: Editora Revista dos Tribunais, 2013. 
TARDE, Gabriel. "Criminalié et santé sociale”. In: Revue philosophique, Ano XX, XXXIX (janeiro a junho, 1895), pp.148-162.

TREVINO, A. Javier. The sociology of law. Classical and contemporary perspectives. New Brunswick, N.J.: Transaction Publishers, 2008. 